\title{
Early discharge of pediatric patients with cancer, fever, and neutropenia with low-risk of systemic infection
}

\author{
Mariana Gil-Veloz', Daniel O. Pacheco-Rosas², Fortino Solórzano-Santos ${ }^{3}$, Miguel A. Villasís-Keever4, \\ Yadira Betanzos-Cabrera ${ }^{5}$ and Guadalupe Miranda-Novales ${ }^{4 *}$ \\ ${ }^{1}$ Hospital Regional de Alta Especialidad del Bajio, León, Guanajuato; ${ }^{2}$ Departamento de Infectología, Unidad Médica de Alta Especialidad, Hospital \\ de Pediatría, Centro Médico Nacional Siglo XXI, Instituto Mexicano del Seguro Social, Mexico City; ${ }^{3}$ Unidad de Investigación en Medicina Basada \\ en Evidencias, Hospital Infantil de México Federico Gómez, Secretaría de Salud, Mexico City; ${ }^{4}$ Unidad de Investigación en Análisis y Síntesis de \\ la Evidencia, Centro Médico Nacional Siglo XXI, IMSS, Coordinación de Investigación, Instituto Mexicano del Seguro Social, Mexico City; \\ ${ }^{5}$ Departamento de Oncología, Unidad Médica de Alta Especialidad, Hospital de Pediatría, Centro Médico Nacional Siglo XXI, Instituto Mexicano \\ del Seguro Social, Mexico City. Mexico
}

\begin{abstract}
Background: Ambulatory therapy in low-risk patients with cancer, fever, and neutropenia seems to be a secure and effective alternative. This study aimed to compare the effectiveness and safety of the antimicrobial treatment in early discharge vs. in-hospital treatment in children with cancer and febrile neutropenia (FN) with low risk of invasive bacterial infection (IBI). Methods: Quasi-experimental design with a historical cohort control group. Children with cancer during an episode of FN and low risk of IBI were included. The control group were inpatient children that received intravenous piperacillin/tazobactam. The experimental group was early discharge patients, who received $48 \mathrm{~h}$ of IV treatment and were switched to oral treatment. Outcomes: fever resolution, readmissions, and mortality. Results: Eighty low-risk FN episodes were included; the median age was 6 years old (2.6-11 years), and $43(54 \%)$ were female. Main diagnoses were solid tumors (52 patients) and leukemia or lymphoma (28 patients). Forty-three patients received in-hospital treatment, and 37 were selected for early discharge (31 patients received ciprofloxacin and six received amoxicillin/clavulanate). Two patients were readmitted, one due to a relapse of fever with tumor progression and the other due to epistaxis. Adverse effects occurred in $21.6 \%$ of the early discharge group and $12 \%$ of the inpatient treatment group $(p=0.04)$. Conclusions: Early discharge in pediatric patients with cancer, fever, and neutropenia is an acceptable and safe alternative for low-risk patients.
\end{abstract}

Key words: Febrile neutropenia. Cancer. Children.

\section{Egreso temprano en pacientes pediátricos con cáncer, fiebre y neutropenia con bajo riesgo de infección sistémica}

\section{Resumen}

Introducción: El tratamiento ambulatorio en pacientes con cáncer, fiebre y neutropenia de bajo riesgo parece ser una alternativa segura y efectiva. El objetivo de este trabajo fue comparar la efectividad y la seguridad del tratamiento antimicrobiano en la modalidad de egreso temprano vs. el tratamiento intrahospitalario en niños con cáncer y neutropenia febril (NF), con

Correspondence:

${ }^{*}$ Guadalupe Miranda-Novales

E-mail: guadalupe.mirandan@imss.gob.mx
Date of reception: 08-03-2018

Date of acceptance: 26-06-2018

DOI: 10.24875/BMHIM.18000015
Disponible en internet: 01-11-2018 Bol Med Hosp Infant Mex. 2018;75:352-357 www.bmhim.com

1665-1146/@ 2018. Hospital Infantil de México Federico Gómez, impreso por Permanyer México SA de CV, todos los derechos reservados. 
bajo riesgo de infección bacteriana invasiva (IBI). Métodos: Diseño cuasi-experimental con un grupo control histórico. Se incluyeron niños con cáncer durante un episodio de NF con bajo riesgo de IBI. El grupo control fue constituido por pacientes que recibieron tratamiento hospitalario con piperacilina-tazobactam intravenosa. Los pacientes en el grupo de egreso temprano recibieron 48 horas de tratamiento intravenoso y egresaron con antimicrobianos por vía oral. Desenlaces: resolución de la fiebre, reingreso al hospital y muerte. Resultados: Se incluyeron 80 pacientes con NF de bajo riesgo; la mediana de edad fue de 6 años; 43 pacientes (54\%) eran de sexo femenino. Los diagnósticos principales fueron tumores sólidos (52) y leucemia o linfoma (28). Cuarenta y tres pacientes recibieron tratamiento hospitalario y 37 fueron seleccionados para egreso temprano. En el grupo de egreso temprano, 31 pacientes recibieron ciprofloxacino y 6 recibieron amoxicilina-clavulanato. Dos pacientes reingresaron, uno por fiebre secundaria a progresión tumoral y otro por epistaxis. Los efectos adversos se presentaron en el $21.6 \%$ de los pacientes en el grupo de egreso temprano y en el $12 \%$ del grupo de tratamiento hospitalario $(p=0.04)$. Conclusiones: El egreso temprano para niños con cáncer y NF de bajo riesgo es una alternativa aceptable y segura.

Palabras clave: Neutropenia febril. Cáncer. Niños.

\section{Introduction}

Chemotherapy-induced neutropenia is one of the most important adverse effects in children with cancer. Low neutrophil counts are associated with an increased risk of bacterial infections. During a febrile neutropenia episode in a cancer patient, standard care includes hospitalization and parenteral administration of broad-spectrum antibiotics. A few decades ago, patients were discharged after remission of fever and the absolute neutrophil count recovery. However, a low proportion of the episodes correspond to a severe infection, and hospital stay might be lengthy and un-necessary ${ }^{1}$. Since the late 1990s, stratification scales have been proposed to discriminate between high- and low-risk patients and consider the later as candidates for outpatient treatment. Despite wide recommendations for adult patients with cancer, there is no consensus for pediatric patients. Almost $50 \%$ of the children with febrile neutropenia could correspond to a group of patients with a low risk of having an invasive bacterial infection. Some centers have applied similar criteria for children and adults, and have selected a low-risk group for outpatient treament ${ }^{1,2}$. Several studies have reported that inpatient treatment is not superior to outpatient management, regarding morbidity and mortality. This modality reduces the risk of hospital-acquired infection and costs and increases the well-being of the child and family with a better quality of life ${ }^{3-6}$.

Outpatient treatment strategies have included early discharge (24-48 h): patients admitted to the hospital for intravenous antimicrobial treatment during the first hours, and then, with negative culture results, switch to oral treatment and complete the scheme (7 days) at home and outpatient treatment with oral antibiotics after the evaluation. Ceftriaxone, cefixime, amoxicillin/clavulanate, and quinolones are some of the antibiotics that have been used in outpatient treatments. In most of the reports, outpatient treatment seems to have similar efficacy as in-hospital treatment, without serious complications $^{5-10}$. In a systematic review by Manji $A$ et al. evaluating outpatient versus in-hospital treatment in low-risk pediatric patients with febrile neutropenia, there was no difference in the outcome: days of fever, treatment failure and adverse effects between the two modalities. The authors conclude that outpatient treatment could be a safe strategy ${ }^{11}$. A later intervention review evaluated whether early discharge $(<5$ days) from in-hospital treatment was not inferior to non-early discharge ( $\geq 5$ days), and whether very early discharge $(<24$ h) was not inferior to early discharge, non-early discharge, or a combination of these in children with cancer and febrile neutropenia ${ }^{12}$. This review concluded that there was no evidence that early discharge or very early discharge were less safe than non-early discharge for patients with a low risk for invasive bacterial infection, but larger studies including other outcomes (costs, quality of life, length of treatment) are needed to confirm these results.

Standard treatment in our hospital for pediatric cancer patients with FN include in-hospital management with broad-spectrum intravenous antibiotics. The aim of this study was to evaluate the effectiveness and security of early discharge and outpatient treatment in low-risk patients with febrile neutropenia.

\section{Methods}

This study was performed in a tertiary care level pediatric center in Mexico City. Design: quasi-experimental with a historical control group. Children with cancer and febrile neutropenia, from 1 to 16 years old were included. The historical control group were children that received inpatient treatment from January 2012 to 
December 2013, with intravenous piperacillin/tazobactam, with negative blood cultures and remission of fever in the first $72 \mathrm{~h}$, and discharged when completed a five-day scheme of intravenous antibiotic (piperacillin/ tazobactam $300 \mathrm{mg} / \mathrm{kg} /$ day). All cases with complete file data were selected by consecutive sampling.

For the experimental group, children admitted with febrile neutropenia from January 2013 to December 2014, were classified as low-risk patients if no evidence of clinical (except upper respiratory tract infection, urinary tract infection or cellulitis) or microbiological infection was present. Also, remission of fever in the first 48 hours after the initiation of the empirical treatment, and none of the following comorbidities: platelet count $<20,000 / \mathrm{mm}^{3}$, hemoglobin $<8 \mathrm{~g} / \mathrm{dl}$, bleeding that compromise hemodynamic stability, hydroelectrolyte imbalance or a renal function less than $50 \%$ of what was expected for the age. Consequently, patients who fulfilled all the criteria were included after their parents had signed a written informed consent. Antibiotics were step down to oral treatment: ciprofloxacin $(20 \mathrm{mg} / \mathrm{kg}$ PO q12h or $750 \mathrm{mg} P O \mathrm{q} 12 \mathrm{~h})$; and in case of upper respiratory tract infection, they received amoxicillin/clavulanate (45 mg/kg/day PO q12h or 500/125 mg PO q8h, for a complete course of 7 days). Patients with known allergy to beta-lactams, unable to take oral medication or living farther than $60 \mathrm{~km}$ from the hospital were excluded.

Non-medical criteria included residence within 2 hours by ground transportation to the hospital and having a local phone number. Parents were instructed to measure the temperature at least four times a day, and register children condition in a dairy-sheet. Two of the researchers were available $24 \mathrm{~h}$ to answer phone calls and resolve any doubt of the parents. Every day a phone call was made to verify the clinical condition, temperature registration, compliance of the oral antibiotic and adverse effects. If the patient outcome was uneventful, the last phone call was made 30 days after the end of treatment.

Fever was defined as axillary temperature $\geq 38.3^{\circ} \mathrm{C}$ or $38^{\circ} \mathrm{C}$ lasting one hour. Severe neutropenia was defined as $\leq 500$ cells $/ \mathrm{mm}^{3}$.

The primary outcome was the resolution of the febrile episode; success was considered if the patient finished the treatment as an outpatient. Failure included the occurrence of any medical complication requiring diagnostic or therapeutic intervention (intolerance to oral medication, the reappearance of fever, bleeding, and hospital readmission to complete antibiotic treatment). Adverse effects of antibiotics were registered.

\section{Statistical methods}

The sample size was calculated with a non-inferiority estimation. The study was designed to detect a difference of $19 \%$ between groups, with a total of 45 patients in each group, with $80 \%$ power, and a significance of $0.05 .{ }^{13}$ Statistical analyses were performed on SPSS software (version 20.0 IMB Statistics). Non-continuous variables were compared using $X^{2}$ and Fisher's exact test, and for continuous variables, Mann Whitney-U test was used for comparisons. A value of $p<0.05$ was considered statistically significant.

The Ethics and Research Review Board approved the study. Written informed consent was obtained from parents and assent from children $\geq 8$ years old.

\section{Results}

Of a total of 83 episodes of fever and neutropenia eligible for inclusion, three were excluded from the early discharge group (37/40) because parents declined to participate. For the analysis, 80 low-risk febrile neutropenia episodes in 84 patients were included (four patients had two episodes); median of age was 6.2 years old (2.6-11); 43 patients (54\%) were female. The main diagnoses were solid tumors (central nervous system and osteosarcoma) in 52 episodes and leukemia or lymphoma in 28 episodes. Forty-three patients received in-hospital treatment and 37 patients qualified for early discharge. General characteristics, neutrophil, platelet, and monocyte counts and length with fever were similar in both groups (Table 1). More patients in the early discharge group received granulocyte-colony stimulating factor (G-CSF) without a statistically significant difference.

In the early discharge group, patients received at least four telephone calls during the follow-up. Thirty-one patients received ciprofloxacin and six received amoxicillin with clavulanic acid. All focalized infections corresponded to upper respiratory tract infections. Time of fever resolution was shorter in the early discharge group (15 vs. $24 \mathrm{~h}, p=0.002$ ). The mean duration of antimicrobial treatment was similar (6.3 days vs. 7.2, $p=0.6)$. Adverse effects were registered in $8 / 37(21.6 \%)$ patients, mainly gastrointestinal manifestations (diarrhea, nausea, vomiting); none of the patients needed to suspend the medication. In the hospitalized group, $12 \%$ presented adverse effects $(p=0.04)$ : four with a headache and one with exanthema. Two patients in the early discharge group were readmitted to the hospital, one due to fever secondary 
Table 1. Characteristics of febrile neutropenia episodes.

\begin{tabular}{|c|c|c|c|}
\hline & Early discharge $(n=37)$ & Inpatient treatment $(\mathrm{n}=43)$ & $\mathbf{p}$ \\
\hline $\begin{array}{l}\text { Age (years)* } \\
\text { Sex } \\
\text { Male } \\
\text { Female }\end{array}$ & $\begin{array}{c}7.7(5.1-11.0) \\
16(43.2 \%) \\
21(56.8 \%)\end{array}$ & $\begin{array}{l}4.5(2.6-7.8) \\
\\
21(48.8 \%) \\
22(51.2 \%)\end{array}$ & $\begin{array}{l}0.17 \\
0.61\end{array}$ \\
\hline \multicolumn{4}{|l|}{ Diagnosis } \\
\hline $\begin{array}{l}\text { Solid tumor } \\
\text { Leukemia/lymphoma }\end{array}$ & $\begin{array}{l}26(70.3 \%) \\
11(29.7 \%)\end{array}$ & $\begin{array}{l}26(60.5 \%) \\
17(39.5 \%)\end{array}$ & 0.35 \\
\hline Days after last cytotoxic chemotherapy* & $10(7-14)$ & $9(6-10)$ & 0.07 \\
\hline Clinical focus or infection & $6(16.2 \%)$ & $11(25.6 \%)$ & 0.30 \\
\hline Neutrophils (cell/ml)* & $29(0-200)$ & $43(9-267)$ & 0.22 \\
\hline Monocytes (cell/ml)* & $100(0-300)$ & $71(14-123)$ & 0.30 \\
\hline Platelet (cell/ml)* & $\begin{array}{c}103,400 \\
(32,900-223,500)\end{array}$ & $\begin{array}{c}67,900 \\
(26,300-221,000)\end{array}$ & 0.74 \\
\hline G-CSF treatment & $27(73 \%)$ & $24(55.8 \%)$ & 0.11 \\
\hline Days using G-CFS* & $4(3-5)$ & $4.5(3-6)$ & 0.13 \\
\hline $\begin{array}{l}\text { Time with a fever before admission } \\
<24 \mathrm{~h} \\
>24 \mathrm{~h}\end{array}$ & $\begin{array}{c}30(81.1 \%) \\
7(18.9 \%)\end{array}$ & $\begin{array}{l}31(72.1 \%) \\
12(27.9 \%)\end{array}$ & 0.34 \\
\hline
\end{tabular}

*Data are presented in median (minimum-maximum values)

G-CSF, granulocyte colony-stimulating factor.

Table 2. Outcome in febrile neutropenia episodes per group of treatment.

\begin{tabular}{|l|c|c|c|}
\hline & Early discharge $(\mathbf{n}=\mathbf{3 7})$ & Inpatient $(\mathbf{n}=\mathbf{4 3})$ & $\mathbf{p}$ \\
\hline Median fever resolution in hours* & $15(2-49)$ & $24(2-60)$ & 0.002 \\
\hline Mean duration of antimicrobial treatment* & $6.3(6-8)$ & $7.2(5-8)$ & 0.6 \\
\hline Adverse effects & $8(21.6 \%)$ & $5(12 \%)$ & 0.04 \\
\hline Relapse of fever & $1(2.7 \%)$ & 0 & 0.46 \\
\hline
\end{tabular}

*Minimum-maximum values.

to tumor progression and another due to epistaxis. In the early discharge group, $94.6 \%$ of patients recovered uneventfully (Table 2). None of the patients died.

\section{Discussion}

During past decades, the standard treatment for pediatric cancer patients with febrile neutropenia included hospitalization to receive broad-spectrum intravenous antibiotics administration. This recommendation led to unnecessary days of hospital stay, as many of the episodes of febrile neutropenia can be classified as low-risk for invasive bacterial infections ${ }^{14-16}$. In adult patients, the identification of a low-risk febrile neutropenia episode at the time of the first presentation is considered a reliable tool to select patients for early or very early discharge. The updated recommendation includes the administration of the initial doses of empirical antimicrobial therapy within one hour of triage and observation for $\geq 4$ hours before discharge. Fluoroquinolones, amoxicillin/clavulanate or clindamycin, in case of beta-lactams allergy, are used for outpatient therapy. Follow-up is mandatory, and if the fever does not defervesce after 2 to 3 days of the initial empirical regimen, 
a re-evaluation should include the option of inpatient treatment ${ }^{17}$. In one of the recent pediatric guidelines, the recommendation for low-risk febrile neutropenia episodes is still in the category of weak recommendation, moderate-quality evidence. Only if the infrastructure can assure careful monitoring and follow-up, the outpatient treatment should be considered ${ }^{18}$.

In this study, by selecting the episodes with remission of fever without clinical or microbiological systemic infection, the early discharge approach proved to be a safe alternative for patients with febrile neutropenia and a low-risk of an invasive bacterial infection. The cause of readmission in two patients was different from a progressive infection, and they did not require intravenous antimicrobials. The evaluation during the first $48 \mathrm{~h}$ with the remission of fever seems to be a good indicator to select the candidates for early discharge. Up to $30 \%$ of the episodes of febrile neutropenia can be attributed to a viral respiratory infection. A randomized clinical trial supports to withhold the antimicrobial treatment if the viral etiology is documented and studies for a bacterial pathogen are negative ${ }^{19}$, which could reduce the selective pressure of resistant bacteria.

However, other hospitals have reported less promising results with the early discharge strategy. A study by Villanueva et al. in the Children's Marcy Hospitals and Clinics, Kansas City, Missouri, reported a readmission rate of $16.7 \%$ and identified in the multivariate analysis that a diagnosis of acute lymphoblastic leukemia, and an absolute neutrophil count of $<100$ cells $/ \mathrm{mm}^{3}$ were independently associated with a higher risk of readmission and infection ${ }^{20}$. Adverse effects of antimicrobial therapy were non-frequent in both groups. Although there were more adverse effects in the early discharge group, these were mild, predominantly gastrointestinal, and associated with oral antibiotics, which in general, were well tolerated.

In this study, we did not analyze hospital costs. Mueller et al. estimated that $40 \%$ of the febrile neutropenia discharges correspond to "short length of stay" and are seldom associated with serious infections. Therefore, they enforce the implementation of early discharge modality for low-risk febrile neutropenia episodes to help decrease the financial burden ${ }^{21}$. Each pediatric oncology center needs to validate the risk stratification scores because the characteristics of patients in developing countries are different from those in nations with higher income ${ }^{22}$.

This study has several limitations. Firstly, the sample was small because the study was performed only in one center. Also, due to the number of eligible candidates with a low-risk febrile neutropenia episode, it was decided to include a cohort of a previous study and to compare them with the early discharge group. C-reactive protein determination is not available in the hospital during the afternoon, night shifts and weekends. Most of the patients did not have a result in the first $24 \mathrm{~h}$ of evaluation, so it was not included. The main characteristics of both groups at the assessment of the febrile neutropenia episodes were similar, but one of the outcomes (remission of fever in hours) had a statistically significant difference. The clinical implication with this variance could not be stated in this study, as basal conditions and principal outcomes did not differ in both groups. The classification of a low-risk febrile neutropenia episode in children needs to be validated in each center, and results cannot be extrapolated to all pediatric patients in different settings.

In conclusion, early discharge modality with oral antimicrobial treatment appears to be a safe alternative for children with a low-risk febrile neutropenia episode. Outpatient treatment of febrile neutropenia is attractive because it can improve patient comfort, and hospital costs could be reduced. By monitoring the patient by telephone, it will be possible to detect complications at an early stage.

\section{Ethical disclosures}

Protection of human and animal subjects. The authors declare that no experiments were performed on humans or animals for this study.

Confidentiality of data. The authors declare that they have followed the protocols of their work center on the publication of patient data.

Right to privacy and informed consent. The authors declare that no identifiable patient data appear in this article.

\section{Conflicts of interest}

The authors declare no conflicts of interest.

\section{Acknowledgments}

Dr. Roberto Bernáldez Ríos † for his support to perform this study.

\section{Funding}

None. 


\section{References}

1. Robinson PD, Lehrnbecher T, Phillips R, Dupuis LL, Sung L. Strategies for empiric management of pediatric fever and neutropenia in patients with cancer and hematopoietic stem-cell transplantation recipients: a systematic review of randomized trials. J Clin Oncol. 2016;34:2054-60.

2. Freifeld AG, Bow EJ, Sepkowitz KA, Boeckh MJ, Ito JI, Mullen CA, et al. Clinical practice guideline for the use of antimicrobial agents in neutropenic patients with cancer: 2010 update by the Infectious Diseases Society of America. Clin Infect Dis. 2011;52:427-31.

3. Mullen CA, Petropoulos D, Roberts WM, Rytting M, Zipf T, Chan KW, et al. Outpatient treatment of fever and neutropenia for low risk pediatric cancer patients. Cancer. 1999;86:126-34.

4. Mullen $C A$. Which children with fever and neutropenia can be safely treated as outpatients? Br J Haematol. 2001;112:832-7.

5. Kaplinsky C, Drucker M, Goshen J, Tamary H, Cohen IJ, Zaizov R. Ambulatory treatment with ceftriaxone in febrile neutropenic children. Isr J Med Sci. 1994;30:649-51.

6. Petrilli A, Altruda Carlesse F, Pires Pereira CA. Oral gatifloxacin in the outpatient treatment of children with cancer fever and neutropenia. $\mathrm{Pe}$ diatr Blood Cancer. 2007;49:682-6.

7. Aquino VM, Herrera L, Sandler ES, Buchanan GR. Feasibility of oral ciprofloxacin for the outpatient management of febrile neutropenia in selected children with cancer. Cancer. 2000;88:1710-4.

8. Park JR, Coughlin J, Hawkins D, Friedman DL, Burns JL, Pendergrass T. Ciprofloxacin and amoxicillin as continuation treatment of febrile neutropenia in pediatric cancer patients. Med Pediatr Oncol. 2003;40:93-8.

9. Paganini HR, Sarkis CM, De Martino MG, Zubizarreta PA, Casimir L, Fernandez $C$, et al. Oral administration of cefixime to lower risk febrile neutropenic children with cancer. Cancer. 2000;88:2848-52.

10. Shenep JL, Flynn PM, Baker DK, Hetherington SV, Hudson MM, Hughes WT, et al. Oral cefixime is similar to continued intravenous antibiotics in the empirical treatment of febrile neutropenic children with cancer. Clin Infect Dis. 2001;32:36-43.

11. Manji A, Beyene J, Dupuis LL, Phillips R, Lehrnbecher T, Sung L. Outpatient and oral antibiotic management of low-risk febrile neutropenia are effective in children-a systematic review of prospective trials. Support Care Cancer. 2012;20:1135-45.

12. Loeffen EAH, Te Poele EM, Tissing WJE, Boezen HM, de Bont ES. Very early discharge versus early discharge versus non-early discharge in children with cancer and febrile neutropenia. Cochrane Database Syst Rev. 2016;2:CD008382. doi: 10.1002/14651858.CD008382.pub2.

13. Piaggio G, Elbourne DR, Altman DG, Pocock SJ, Evans SJW, CONSORT Group. Reporting of noninferiority and equivalence randomized trials: an extension of the CONSORT statement. JAMA. 2006;295:1152-60.

14. Santolaya ME, Alvarez AM, Becker A, Cofré J, Enríquez N, O’Ryan M, et al. Prospective, multicenter evaluation of risk factors associated with invasive bacterial infection in children with cancer, neutropenia, and fever. J Clin Oncol. 2001;19:3415-21.

15. Santolaya ME, Alvarez AM, Avilés CL, Becker A, Cofré J, Cumsille MA, et al. Early hospital discharge followed by outpatient management versus continued hospitalization of children with cancer, fever, and neutropenia at low risk for invasive bacterial infection. J Clin Oncol. 2004;22:3784-9.

16. Klastersky J, Paesmans M. The Multinational Association for Supportive Care in Cancer (MASCC) risk index score:10 years of use for identifying low-risk febrile neutropenic cancer patients. Support Care Cancer. 2013:21:1487-95.

17. Taplitz RA, Kennedy EB, Bow EJ, Crews J, Gleason C, Hawley DK, et al. Outpatient management of fever and neutropenia in adults treated for malignancy: American Society of Clinical Oncology and Infectious Diseases Society of America Clinical Practice Guideline Update. J Clin Oncol. 2018;36:1443-53. doi: 10.1200/JCO.2017.77.6211.

18. Lehrnbecher T, Robinson P, Fisher B, Alexander S, Ammann RA, Beauchemin M, et al. Guideline for the management of fever and neutropenia in children with cancer and hematopoietic stem-cell transplantation recipients: 2017 update. J Clin Oncol. 2017;35:2082-94.

19. Santolaya ME, Alvarez AM, Acuña M, Avilés CL, Salgado C, Tordecilla J, et al. Efficacy and safety of withholding antimicrobial treatment in children with cancer, fever and neutropenia, with a demonstrated viral respiratory infection: a randomized clinical trial. Clin Microbiol Infect. 2017;23:1173-8.

20. Villanueva MA, August KJ. Early discharge of neutropenic pediatric oncology patients admitted with fever. Pediatr Blood Cancer. 2016;63: 1829-33.

21. Mueller EL, Croop J, Carroll AE. Fever and neutropenia hospital discharges in children with cancer: a 2012 update. Pediatr Hematol Oncol. 2016; 33:39-48.

22. Das A, Trehan A, Oberoi S, Bansal D. Validation of risk stratification for children with febrile neutropenia in a pediatric oncology unit in India. Pediatr Blood Cancer. 2017;64. doi: 10.1002/pbc.26333. 